and $75 \mathrm{~g}$. aspartic acid were obtained after 36 hours of electrolysis. The acid was then recrystallized and analyzed.

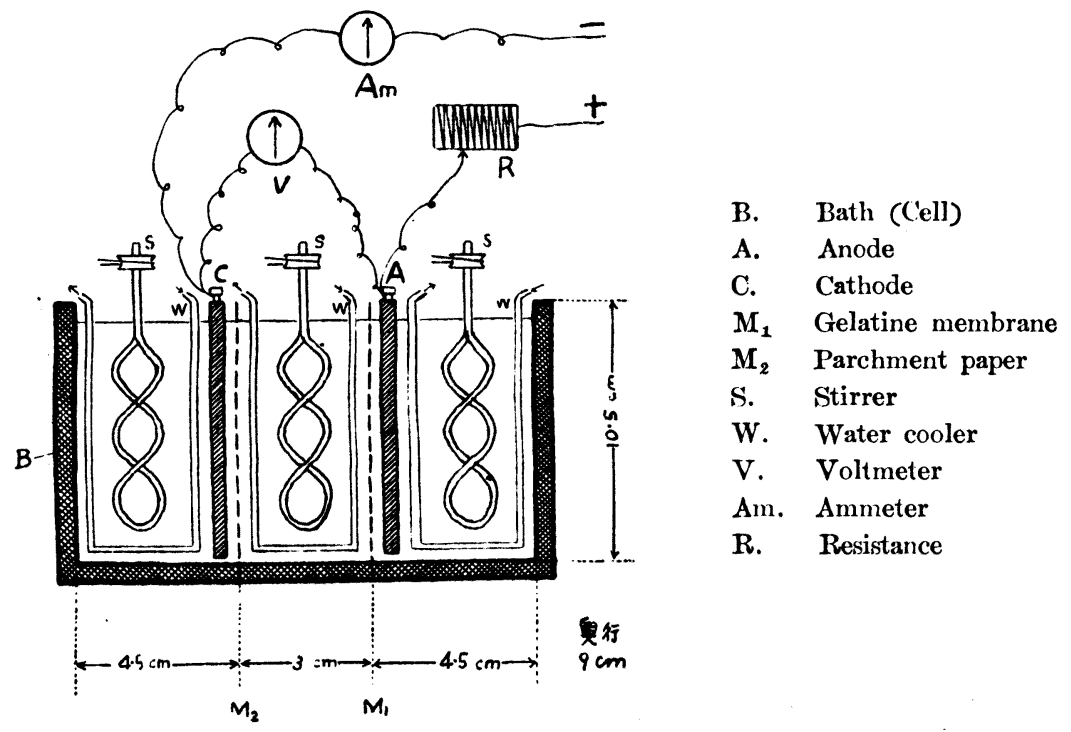

\title{
STUDIES ON ACIDS FORMED BY RHIZOPUS SPECIES. PART II.
}

\author{
FORMATION OF ETHYL ALCOHOL FROM \\ TARTARIC OR FUMARIC ACID.
}

By Teizo Takahashi, Kinichiro Sakaguehi and Toshinobu Asai.

\section{(Received July 15th., 1925)}

Further five species of Rhizopus of various origin were studied. One of them, Rh. japonicus Saito, formed mainly fumaric acid with trace of lactic acid, while $\mathrm{Rh}$. shangheiensis Yamazaki gave both these acids in a reversed proportion. The other three species, Rh. nodosus Yam., Rh. Batatas Nakazawa, Rh. Tritici Saito formed both lactic and fumaric acids.

I actic acid formed by these strains was l-lactic acid as we have mentioned in the previous report. 
In the volatile products there were found beside ethyl alcohol both formic and acetic acids. The quantitative determination of acetic acid was made of this distillate after the destruction of formic acid by $\mathrm{K}$-bichromate and sulphuric acid. The quantity of formic acid was calculated from the difference of the total acidity and that due to the acetic acid.

In a previous report the presence of malic acid was mentioned from the result of qualitative test. This acid has now been isolated and accurately identified by Dakin's ${ }^{(1)}$ method. Cinchonin- $l$-malate thus obtained melted at $197-198^{\circ} \mathrm{C}$ (uncorr.), as given by Dakin. ${ }^{(2)}$

The results of the analyses are shown in the following table :-

\begin{tabular}{|c|c|c|c|c|c|}
\hline Species of Rhizopus, & $\begin{array}{c}\mathrm{R}: \\
\text { japonicus }\end{array}$ & $\begin{array}{c}\mathbf{R} . \\
\text { nodosus }\end{array}$ & $\begin{array}{c}\text { IR. } \\
\text { Batatas }\end{array}$ & $\begin{array}{c}\mathrm{R} . \\
\text { Tritici }\end{array}$ & $\begin{array}{l}\text { R. shang- } \\
\text { heiensis }\end{array}$ \\
\hline Weight of fungus in $1 \mathrm{~L}$. medium. & $1.109 \mathrm{gr}$. & 1.320 & 1.268 & 1.455 & 1.002 \\
\hline Sugar consumed. & $38.4 \mathrm{gr}$. & 47.5 & 46.8 & 37.8 & 54.0 \\
\hline $\begin{array}{l}\text { Acidity of medium expressed in c.c. of } 1 / 10^{\mathrm{n}} \\
\mathrm{NaOH} \text { to neutralize } 10 \text { c.c. of it. }\end{array}$ & 14.4c.c. & 22.2 & 24.6 & 18.6 & 21.6 \\
\hline $\begin{array}{l}\text { Quantity of acid ppted as } \mathrm{Pb} \text {-salt in the residue } \\
\text { of ether extract expressed in c.c. of } 1 / 10^{\mathrm{n}} \\
\mathrm{NaOH} \text {. }\end{array}$ & 32.8c.c. & 6.8 & 3.3 & 24.2 & 4.9 \\
\hline 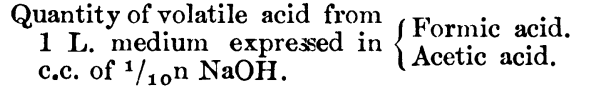 & 1.0c.c. & $\begin{array}{r}7.8 \\
12.2\end{array}$ & $\begin{array}{r}2.0 \\
8.0\end{array}$ & $\begin{array}{l}13.4 \\
11.6\end{array}$ & $\begin{array}{l}2.3 \\
1.7\end{array}$ \\
\hline Alcohol formed (wt. \%) & $0.67 \%$ & 0.16 & 0.29 & 0.54 & 0.23 \\
\hline $\begin{array}{l}\text { Acid in ether extract } \\
\text { from } 1 \mathrm{~L} \text {. medium. }\end{array} \quad\left\{\begin{array}{l}\text { Fumaric acid. } \\
\text { Lactic acid. }\end{array}\right.$ & $\begin{array}{l}6.07 \mathrm{gr} . \\
\text { trace }\end{array}$ & $\begin{array}{l}0.10 J \\
17.1 \mathrm{gr} .\end{array}$ & $\begin{array}{r}0.059 \\
18.0\end{array}$ & $\begin{array}{r}0.041 \\
13.9\end{array}$ & $\begin{array}{r}\text { trace } \\
16.5\end{array}$ \\
\hline Zn-lactate $\quad\left\{\begin{array}{l}\text { Water of crystallisation. } \\
{[\alpha]_{1}^{20}}\end{array}\right.$ & & $\begin{array}{r}13.05 \% \\
+6.75^{\circ}\end{array}$ & $\begin{array}{r}13.14 \\
+\quad 7.1\end{array}$ & $\begin{array}{r}12.91 \\
+6.81\end{array}$ & $\begin{array}{r}13.21 \\
+6.85\end{array}$ \\
\hline Remarks & 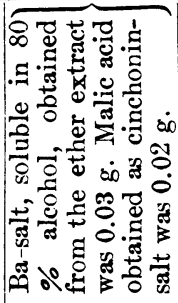 & & & & 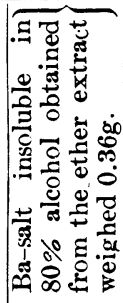 \\
\hline
\end{tabular}

The formation of lactic acid and alcohol from fumarate was affirmed in in the culture of Rh. G. 36 in the medium consisting of : water 100 c.c., peptone $0.3 \mathrm{~g}$. and $\mathrm{K}$-fumarate $2.5 \mathrm{~g}$. besides mineral matters. Iactic acid amounting to $0.063 \mathrm{~g}$. was determined by Ripper's method. ${ }^{(3)}$ The quantity of ethyl alcohol was too small to be determined quantitatively althongh it

( 1 ) and ( 2). Dakin: Jourual of Biol. chem. Vol LIX, No 1, p. 7. 1924.

(3) Ripper : Bioch. Zeit. 42, S. 91-104, 1912. 
gave iodoform when treated by iodine and sodium hydroxide. The change of fumaric acid into lactic acid may be shewn in accordance with equation :-

$$
\begin{gathered}
\mathrm{HOOC} \cdot \mathrm{C} \cdot \mathrm{H} \\
\mathrm{H} \cdot \mathrm{C} \cdot \mathrm{COOH}
\end{gathered}+\underset{\mathrm{OH}}{\mathbf{H}}=\mathrm{CO}_{2}+\underset{\mathrm{COOH}}{\stackrel{\mathrm{H} \cdot \mathrm{C} \cdot \mathrm{OH}}{\mathrm{CH}_{3}}}\left[\begin{array}{l}
\mathrm{I} \\
\mathrm{CH}^{2}
\end{array}\right.
$$

As to the production of ethyl alcohol the most probable explanation is the intermediate formation of pyruvic acid from lactic acid, as already proved by Kayser $^{(4)}$ in the case of yeasts.

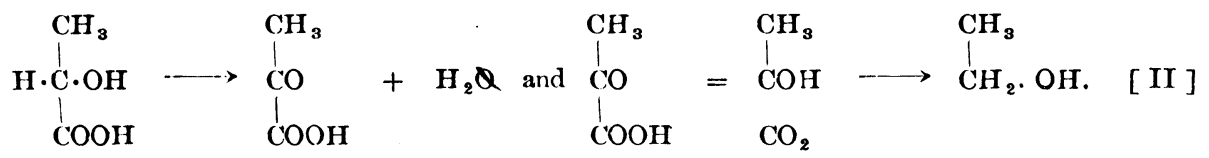

The change of tartarate into fumarate and alcohol was confirmed by the culture of $\mathrm{Rh}$. Oryzea in the medium consisting of: water 1000 c.c., $\mathrm{K}_{2} \mathrm{HPO}_{4}$ 0.15 g., $\mathrm{KH}_{2} \mathrm{PO}_{4} 0.15$ g., $\mathrm{MgSO}_{4} 0.1$ g., $\mathrm{CaCl}_{2} 0.1$ g., $\mathrm{Fe}_{2} \mathrm{Cl}_{6}$ and $\mathrm{NaCl}$ trace, $\mathrm{Na}$ or K-tartarate $20 \mathrm{~g}$., peptone either 1 or $3 \mathrm{gr}$., or some times $2 \mathrm{~g}$. and $\mathrm{CaCO}_{3} 20 \mathrm{~g}$.

Fumaric acid isolated from this culture melted at $279^{\circ} \mathrm{C}$ (uncor.) in a sealed tube and gave a characteristic colour reaction found by the authors. ${ }^{(5)}$ Its silber salt dried at $110^{\circ} \mathrm{C}$ was analysed and gave the following data :-

\begin{tabular}{|c|c|c|c|c|}
\hline $\begin{array}{c}\text { Subst. taken. } \\
0.2485 \mathrm{~g} \text {. }\end{array}$ & $\begin{array}{c}\mathrm{AgCl} . \\
0.2242 \mathrm{~g} .\end{array}$ & $\begin{array}{c}\text { Ag } \\
\text { Found } \\
\text { Calcul. }\end{array}$ & as & $\begin{array}{l}\mathrm{C}_{4} \mathrm{H}_{2} \mathrm{O}_{4} \mathrm{Ag}_{2} \\
65.57 \% \\
65.44 \%\end{array}$ \\
\hline
\end{tabular}

Its dimethyl ester melted at $100-101^{\circ} \mathrm{C}$. The production of the fumaric acid from tartaric acid may be expressed by the following mode :-

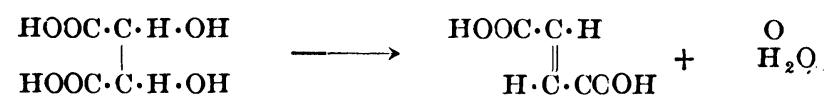

The formation of ethyl alcohol by this fungus seems to take place most reasonably in accordance with the equations I and II. If we accept the old theory that lactic acid is an intermediate product of alcoholic fermentation is proved in this case too, as in the case of yeast done by Kayser. ${ }^{(4)}$

(July 10, 1925).

(4) Kayser : Comp. R. Tome 176. No. 22. p. 1663. 1923.

(5) Authors method will be published later. 